\title{
Aftermath of COVID-19 and Critical Care in India
}

\author{
Rajesh Panda ${ }^{1} \oplus$, Divya Hirolli² ${ }^{\oplus}$, Dalim K Baidya ${ }^{3}$
}

\begin{abstract}
The coronavirus disease-2019 (COVID-19) pandemic had overwhelmed the healthcare system and forced many patients to be treated at home with oxygen, antibiotics, and steroids, particularly during the second wave. There was increased misuse of antimicrobials in hospitals as well as unguarded self-prescription of these medications among the common people. We are likely to see an increase in the incidence of antimicrobial resistance (AMR), change in the susceptibility pattern of the organisms causing community-acquired infections, and an increase in opportunistic bacterial, tubercular, viral, and fungal infections.

Keywords: Antimicrobial resistance, COVID-19, Opportunistic infection.

Indian Journal of Critical Care Medicine (2021): 10.5005/jp-journals-10071-23987
\end{abstract}

The coronavirus disease-2019 (COVID-19) pandemic overwhelmed the healthcare system all over the world and so far affected more than 300 million people and witnessed nearly 4.0 lakh deaths in India. ${ }^{1}$ Reduced availability of hospital beds, particularly during the second wave, forced many patients to be treated at home with oxygen, antibiotics, and steroids. In a country with a population of over 136 crores, and the existing low doctor-patient ratio, added on by the fear of the pandemic fueled and flared by the social media with prescriptions containing antivirals, antibiotics, and steroids circulating in various public platforms like Facebook and YouTube, we witnessed an unguarded self-prescription of these medications among the common people.

This can have various lasting consequences, including antimicrobial resistance (AMR), varying susceptibility pattern, and an increase in opportunistic infection. AMR is a major threat to public health and is estimated to cause 10 million deaths annually by 2050 . India carries one of the largest burdens of drug-resistant pathogens worldwide. ${ }^{2}$ Annually, more than 50,000 newborns are estimated to die from sepsis due to pathogens resistant to first-line antibiotics. ${ }^{3}$ Van Boeckel et al. reported that India was the largest consumer of antibiotics with $12.9 \times 10^{9}$ units (10.7 units per person) sold in the year 2010. ${ }^{4}$ The current COVID-19 pandemic may have worsened the issue of growing antibiotic resistance. ${ }^{5}$

In hospitalized COVID-19 patients, it is often difficult to differentiate viral inflammatory flare from secondary bacterial infection, which can eventually lead to increased use of empirical broad-spectrum antibiotics. Studies have shown that as many as $70-90 \%$ patients of COVID-19 received antibiotics, ${ }^{5,6}$ whereas the incidence of coinfections was $7.2 \%$ and hospital-acquired infections $4.2 \%$ only. ${ }^{7}$ Vijay et al. reported that in their retrospective study on secondary infections among the hospitalized COVID-19 patients in ten different hospitals of the Indian Council of Medical Research, antimicrobial resistance surveillance network showed only $3.6 \%$ of COVID-19 patients developed secondary bacterial or fungal infections. However, mortality among those with secondary infections was $56.7 \%$ against an overall mortality of $10.6 \% .^{8}$ This could have contributed to the augmented use (misuse) of antibiotics.

Although increased antibiotic use in COVID-19 has been high all over the world, it may have been of much greater magnitude in India. The novelty of the disease and lack of clear guidelines
${ }^{1}$ Department of Anesthesiology and Critical Care, All India Institute of Medical Sciences, Bhopal, Madhya Pradesh, India

${ }^{2,3}$ Department of Anesthesiology, Pain Medicine and Critical Care, All India Institute of Medical Sciences, New Delhi, India

Corresponding Author: Dalim K Baidya, Department of Anesthesiology, Pain Medicine and Critical Care, All India Institute of Medical Sciences, New Delhi, India, e-mail: dalimkumar.ab8@gmail.com

How to cite this article: Panda R, Hirolli D, Baidya DK. Aftermath of COVID-19 and Critical Care in India. Indian J Crit Care Med 2021; 25(10):1173-1175.

Source of support: Nil

Conflict of interest: None

on the management have led to the increased use of antibiotics like doxycycline and azithromycin even in mild COVID-19 patients treated at home in our country. The Infectious Disease Society of America recommends macrolides for the treatment of communityacquired pneumonia with and without comorbidities. However, it got popular in the COVID-19, considering its antiviral property due to its ability to decrease the viral entry into the cell and the immunomodulatory property. ${ }^{9}$ With the additional antibacterial properties to combat the coinfections, azithromycin was being prescribed to many COVID-19 patients with and without hospital admission. However, the results of COALITION-II trial have shown that the addition of azithromycin to the existing standard of care does not appear to improve the outcome. ${ }^{10}$ Doxycycline is usually prescribed as a part of empiric treatment for atypical bacterial pneumonia or community-acquired pneumonia as per evidence-based clinical practice guidelines. ${ }^{11}$ Doxycycline was also being prescribed even in most mild COVID-19 cases all over India. Considering the widespread use of antibiotics, we anticipate a rise in the drug-resistant pathogenic organisms. In addition, antibiotics also cause disruption of the human microbiome, which eventually leads to dysfunctions in nutrient supply, vitamin production, and protection from pathogenic organism ultimately increasing susceptibility to infections. ${ }^{12}$ The pathogens causing communityacquired infections in the future may potentially be more resistant to the antibiotics used in pre-COVID times. The genomic revolution has enabled thousands of strain-specific, whole-genome

(c) The Author(s). 2021 Open Access This article is distributed under the terms of the Creative Commons Attribution 4.0 International License (https://creativecommons. org/licenses/by-nc/4.0/), which permits unrestricted use, distribution, and non-commercial reproduction in any medium, provided you give appropriate credit to the original author(s) and the source, provide a link to the Creative Commons license, and indicate if changes were made. The Creative Commons Public Domain Dedication waiver (http://creativecommons.org/publicdomain/zero/1.0/) applies to the data made available in this article, unless otherwise stated. 
sequencing, and this data informatics can be used to study the spread and acquisition of AMR. The whole-genome sequencing can be used to predict the minimum inhibitory concentrations of various antibiotics, ${ }^{13}$ and the routine use of macrolides and doxycycline as in pre-COVID era may need to be reconsidered for community-acquired infections.

The imprudent use of steroids and immunomodulatory drugs like tocilizumab could lead to the reactivation of latent bacterial and viral infections. Immunosuppression by steroids added on by broadspectrum antibiotics leads to exhaustion of the friendly commensals making the body an excellent ground for the opportunistic infections, which is already witnessed by the unforeseen spurt of mucormycosis cases in the COVID-19 second wave. Mucormycosis infection of the sinuses is a form of life-threatening invasive fungal sinusitis that typically affects immunocompromised individuals with an impaired neutrophilic response. Possible reasons explained for the increase in these cases were immunosuppression caused by COVID-19, extensive use of steroids, and broad-spectrum antibiotics. ${ }^{14}$

It is a known fact that steroids cause qualitative and quantitative defects in the immune system, resulting in an increased risk of tuberculosis because of reactivation of the latent infection, relapse, or acquiring new infection. ${ }^{15}$ With most of the national resources diverted to COVID-19 management, there has been a consequential hit on the delivery of various tuberculosis prevention, surveillance, and treatment programs. Lockdown and public health guidelines have resulted in burdening of the traditional management of tuberculosis. ${ }^{16}$ Though India had aimed to end tuberculosis by 2025 , the present COVID-19 crisis with its direct and indirect impact on tuberculosis can make that difficult, ${ }^{17}$ and we can even foresee a rise in the tuberculosis cases in India following the COVID-19 second wave.

Reactivation of viral infections post-immunosuppression is another concern. Hepatitis $B$ is a major global healthcare challenge with a wide number of the world population with current or past infection, and immunosuppression is considered a major factor for reactivation. Reactivation of hepatitis $B$ is more common in individuals who are HBsAg positive, as opposed to HBsAg negative, and is defined as an increase in viral load of at least 100 -fold. This can manifest with transaminitis and in some cases may lead to acute liver failure ${ }^{18}$ and should be considered in the differential diagnosis of patients presenting with acute liver failure during/following the pandemic. Cytomegalovirus (CMV) is another well-known pathogen in immunosuppression and can cause reactivation disease in critically ill or post-COVID-19 patients. ${ }^{19}$ CMV manifestations in COVID-19 patients have already been reported in national media from a leading tertiary care hospital of Delhi. ${ }^{20}$ Other viruses capable of such opportunistic infection include herpes simplex virus, varicella-zoster virus, Epstein-Barr virus, human herpes virus type 6, JC virus, enterovirus, and measles virus. ${ }^{21} \mathrm{~A}$ high index of suspicion for viral reactivation disease should be maintained in post-COVID-19 patients following the second wave of COVID-19.

To conclude, following the COVID-19 second wave, we are likely to see an increase in the incidence of antibiotic resistance, change in the susceptibility pattern of the organisms causing communityacquired infections, and an increase in opportunistic bacterial, tubercular, viral, and fungal infections.

\section{OrCID}

Rajesh Panda $\odot$ https://orcid.org/0000-0001-7123-876X Divya Hirolli $\odot$ https://orcid.org/0000-0001-6213-300X Dalim K Baidya @ https://orcid.org/0000-0001-7811-7039

\section{References}

1. World Healrth Organization. Available from: https://www.who.int/ countries/ind/ [Accessed on June 30, 2021].

2. Dixit A, Kumar N, Kumar S, Trigun V. Antimicrobial resistance: progress in the decade since emergence of New Delhi metallo- $\beta$-lactamase in India. Indian J Community Med 2019;44(1):4-8. DOI: 10.4103/ijcm. IJCM_217_18.

3. Laxminarayan R, Duse A, Wattal C, Zaidi AK, Wertheim HF, Sumpradit N, et al. Antibiotic resistance-the need for global solutions. Lancet Infect Dis 2013;13(12):1057-1098. DOI: 10.1016/ S1473-3099(13)70318-9.

4. Van Boeckel TP, Gandra S, Ashok A, Caudron Q, Grenfell BT, Levin SA, et al. Global antibiotic consumption 2000 to 2010: an analysis of national pharmaceutical sales data. Lancet Infect Dis 2014;14(8): 742-750. DOI: 10.1016/S1473-3099(14)70780-7. PMID: 25022435.

5. Garg SK. Antibiotic misuse during COVID-19 pandemic: a recipe for disaster. Indian J Crit Care Med 2021;25(6):617-619. DOI: 10.5005/ jp-journals-10071-23862.

6. Langford BJ, So M, Raybardhan S, Leung V, Soucy JR, Westwood D, et al. Antibiotic prescribing in patients with COVID-19: rapid review and meta-analysis. Clin Microbiol Infect 2021;27(4):520-531. DOI: 10.1016/j.cmi.2020.12.018.

7. Garcia-Vidal C, Sanjuan G, Moreno-García E, Puerta-Alcalde P, GarciaPouton N, Chumbita M, et al.; COVID-19 Researchers Group. Incidence of co-infections and superinfections in hospitalized patients with COVID-19: a retrospective cohort study. Clin Microbiol Infect 2021;27(1):83-88. DOI: 10.1016/j.cmi.2020.07.041. PMID: 32745596; PMCID: PMC7836762.

8. Vijay S, Bansal N, Rao BK, Veeraraghavan B, Rodrigues C, Wattal C, et al. Secondary infections in hospitalized COVID-19 patients: Indian experience. Infect Drug Resist 2021;14:1893-1903. DOI: 10.2147/IDR. S299774.

9. Yao X, Ye F, Zhang M, Cui C, Huang B, Niu P, et al. In vitro antiviral activity and projection of optimized dosing design of hydroxychloroquine for the treatment of severe acute respiratory syndrome coronavirus 2 (SARS-CoV-2). Clin Infect Dis 2020;71(15):732-739. DOI: 10.1093/cid/ ciaa237.

10. Oldenburg CE, Doan T. Azithromycin for severe COVID 19. Lancet 2020;396(10256):936-937. DOI: 10.1016/S0140-67369(20)31863-8.

11. Metlay JP, Waterer GW, Long AC. Diagnosis and treatment of adults with community-acquired pneumonia. Am J Respir Crit Care Med 2019;200(7):e45-e67. DOI: $10.1164 / \mathrm{rccm} .201908-1581 S T$.

12. Guarner F, Malagelada JR. Gut flora in health and disease. Lancet 2003; 361(9356):512-519. DOI: 10.1016/S0140-6736(03)12489-0.

13. Monk JM. Predicting antimicrobial resistance and associated genomic features from whole-genome sequencing. J Clin Microbiol 2019;57(2):e01610-e01618. DOI: 10.1128/JCM.01610-18.

14. Sharma S, Grover M, Bhargava S, Samdani S, Kataria T. Post coronavirus disease mucormycosis: a deadly addition to the pandemic spectrum. J Laryngol Otol 2021;135(5):442-447. DOI: 10.1017/S0022215121000992.

15. Patil S, Jadhav A. Short course of high-dose steroids for anaphylaxis caused flare up of tuberculosis: a case report. J Transl Int Med 2019;7(1):39-42. DOI: 10.2478/jtim-2019-0008.

16. Jain VK, lyengar KP, Samy DA, Vaishya R. Tuberculosis in the era of COVID-19 in India. Diabetes Metab Syndr 2020;14(5):1439-1443. DOI: 10.1016/j.dsx.2020.07.034.

17. Behera D. Tuberculosis, COVID-19 and the end tuberculosis strategy in India. Lung India 2020;37(6):467-472. DOI: 10.4103/lungindia. lungindia_544_20.

18. Koffas A, Dolman GE, Kennedy PT. Hepatitis B virus reactivation in patients treated with immunosuppressive drugs: a practical guide for clinicians. Clin Med (Lond) 2018;18(3):212-218. DOI: 10.7861/ clinmedicine.18-3-212.

19. Cook CH. Cytomegalovirus reactivation in "immunocompetent" patients: a call for scientific prophylaxis. J Infect Dis 2007;196(9): 1273-1275. DOI: 10.1086/522433. 
20. Five Covid patients at Delhi's Ganga Ram Hospital suffered rectal bleeding due to CMV infection, one dies. Times of India; June 29, 2021. Available from: https://timesofindia.indiatimes.com/city/delhi.
21. Kennedy PGE. An overview of viral infections of the nervous system in the immunosuppressed. J Neurol 2020;268:3026-3030. DOI: 10.1007/ s00415-020-10265-z. 